\title{
14. Deutscher IT-Sicherheitskongress
}

Der 14. Deutsche IT-Sicherheitskongress findet vom 19. bis 21. Mai 2015 in der Stadthalle Bad-Godesberg in Bonn statt. Angriffe auf die Informationsinfrastrukturen im CyberRaum werden zunehmend komplexer und professioneller. Gleichzeitig nimmt die IT-Abhängigkeit von Unternehmen, Staat und Bürgern und damit das Schadenspotenzial stetig zu. Dabei zeigt sich einmal mehr das breite Spektrum möglicher Angriffspfade, das den Angreifern nach wie vor einen nicht zu unterschätzenden Vorteil verschafft. Schließlich muss es das Ziel sein, die Systeme im Cyber-Raum möglichst gegen alle vorhersehbaren Gefährdungen gleichzeitig ausreichend abzusichern, da dem Angreifer die Auswahl des für seine Zwecke geeigneten Angriffsvektors weitgehend freisteht.

Um Cyber-Angriffen wirksam zu begegnen, ist eine intensive Kooperation von Staat, Wirtschaft und Wissenschaft erforderlich. Es gilt, vorhandenes Wissen zu bündeln und neue Erkenntnisse zu gewinnen, um angesichts neuer Angriffsszenarien vorbereitet $\mathrm{zu}$ sein.

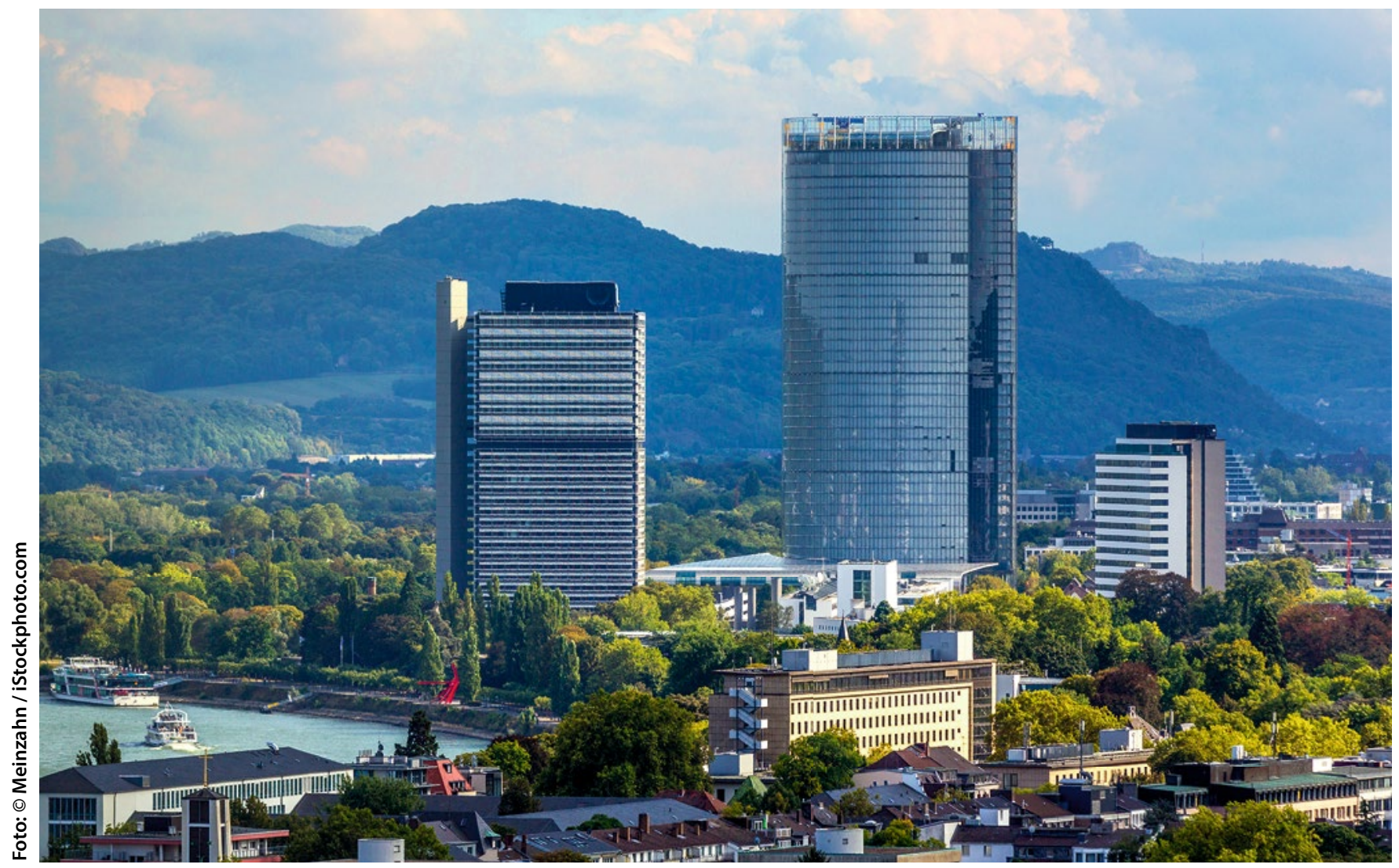

Daher lautet das Motto des 14. Deutschen IT-Sicherheitskongresses: „Risiken kennen, Herausforderungen annehmen, Lösungen gestalten“.

Mit über 600 Fachbesuchern (im Jahre 2013) ist der Deutsche IT-Sicherheitskongress, den das Bundesamt für Sicherheit in der Informationstechnik (BSI) alle zwei Jahre veranstaltet, eine feste Größe im Veranstaltungskalender der IT-Sicherheitsbranche.

Drei Tage lang diskutieren die Teilnehmer über den Stand der nationalen und internationalen Entwicklung zur IT-Sicherheit. Ziel des Kongresses ist es, das Thema IT-Sicherheit aus unterschiedlichen Blickwinkeln zu beleuchten und Lösungsansätze vorzustellen und weiterzuentwickeln. Eine begleitende Ausstellung ergänzt das Vortragsprogramm.

Die Beiträge rund um Fragen der IT-Sicherheit zeichnen sich durch Praxisnähe und eine auch für Laien verständliche Sprache aus.

Weitere Informationen unter: www.bsi.bund.de/DE/Aktuelles/Veranstaltungen/IT-Sicherheitskongress/IT-Sicherheitskongress_node.html 